\title{
La elite profesional docente como fracción intelectual subordinada. Argentina: 1852-1900
}

\author{
Ricardo González Leandri \\ Escuela de Estudios Hispano-Americanos, \\ CSIC. Sevilla
}

La centralización y el impulso a la "educación patriótica", diseñados para lograr una rápida homogeneidad cultural entre la población fueron las características clave del sistema público de educación elemental que se consolidó en Argentina en la segunda mitad del siglo XIX. Ellas auparon hacia su cúspide a un sector de funcionarios "normalistas" que tendieron a considerarse como una elite intelectual más apegada a los destinos del Estado que a los de la profesión de la que formaban parte.

Sin embargo, en contra de sus expectativas, no pudieron dejar de ser un grupo intelectual subordinado. Los motivos deben buscarse en el monopolio que los "doctores", pertenecientes en general a los sectores sociales más encumbrados, ejercieron sobre los espacios en los que se definían las abstracciones académicas y las políticas educativas y en las estrategias de distinción que los propios "normalistas" aplicaron sobre los demás docentes, que los debilitó como sector profesional.

El propósito de este artículo es analizar algunos aspectos del complejo entramado de relaciones establecido por un sector de funcionarios educativos con aspiraciones a convertirse en una elite intelectual con la consolidación de un sistema de enseñanza elemental público y centralizado en Argentina en la segunda mitad del siglo XIX, sistema considerado por sus dirigentes como un elemento clave del ingreso del país en un estado de "Paz y Administración" dentro de un marco de "Orden y Progreso".

El conjunto de actores sociales e instituciones que se conoce como "sistema educativo" representa una dimensión decisiva de los estados modernos y deriva en gran parte su importancia del hecho de tratarse de una herramienta centralizada de reproducción y búsqueda de homogeneidad cultural dentro de unos territorios nacionales específicos. Se trata, a su vez de cuestiones de notable relevancia en la propia formación histórica de esos estados, tal como lo han puesto de manifiesto aquellos investigadores que se han ocupado en detalle de su estudio, como Oscar Oslak para el caso argentino. $^{1}$

1 Oszlak, Oscar: La formación del estado argentino, Buenos Aires 1987; Gellner, Ernest: Naciones y nacionalismo, Madrid 1983. 
Conviene además resaltar otras cuestiones. La educación en cuanto "sistema" y "proceso", presupone en sus distintas fases la intersección de diferentes problemáticas sociales e institucionales que le otorgan su sentido histórico específico. Esto a su vez se relaciona de manera íntima con el hecho de que la promoción de un mínimo grado de homogeneidad cultural y la difusión de conocimientos básicos demandados por el mercado de trabajo, se topan en su puesta en práctica con los gestos y movimientos de aquellos que pretenden definirse a sí mismos como especialistas y que por tanto pugnan por que se los considere como "educadores legítimos". Pero la cuestión se torna aún más compleja dado que por sus propias características y orientaciones el sistema educativo implica por definición una densa trama discursiva que, si bien tiene a lo pedagógico como centro, se entreteje también alrededor de otros criterios y saberes. ${ }^{2}$

El análisis histórico de la especificidad educativa argentina, deberá priorizar entonces el estudio del surgimiento y consolidación de sus instituciones características y de sus grupos jerarquizados y a veces antagónicos, cada uno con sus propias prácticas y discursos y sus intentos "profesionalizadores". ${ }^{3}$ Dado que actúan como importante telón de fondo de todo el proceso, es fundamental tener en cuenta las complejas y paradójicas relaciones históricas que el sistema educativo mantiene históricamente con los intelectuales. En efecto, estos representan uno de sus productos más importantes, aunque sin embargo con el auge de la llamada modernidad su campo o esfera de acción adquiere rasgos cada vez más autónomos y específicos.

Conviene aclarar por último que el sistema público de educación se consolidó en Argentina entre 1880 y los últimos años del siglo XIX, cuan-

2 Proyectando la caracterización que Josefina Ludmer realiza de la Criminología, puede afirmarse que la pedagogía, ciencia en formación entonces, era (y es) una ciencia "intertextual". En buena medida ambas ciencias intentaban dar respuestas desde distintos ángulos a similares preocupaciones y proyectos sociales y estatales. No fue en absoluto casual que intelectuales de primera línea como los hermanos Ramos Mejía, Bunge y otros hayan frecuentado ambos campos tanto en su producción académica como en su actividad como funcionarios. Consúltese: Ludmer, Josefina: El cuerpo del delito. Un manual, Buenos Aires 1999.

$3 \mathrm{Al}$ plantear estas cuestiones trato de inscribir en el análisis toda la complejidad señalada por Abbot. En cuanto al problema de la legitimidad y de la autonomía de los practicantes de una actividad determinada y específica es necesario remitirse a la teoría de los campos de Pierre Bourdieu y en especial a las particularidades que señala para el campo intelectual. Abbott, Andrew: The System of Professions, Chicago 1989; Bourdieu, Pierre: Cosas Dichas, Buenos Aires 1988 y Campo del poder y campo intelectual, Buenos Aires 1983. Puede consultarse también Calhoub, Craig, LiPuma, Edward y Postone, Moishe: Bourdieu. Critical Perspectives, Chicago, 1993. 
do lograron articularse de manera sólida y fluida planteamientos pedagógicos e institucionales previos. A pesar de la irregularidad de su puesta en marcha y de desacuerdos de importancia entre sus precursores intelectuales, ejecutores y beneficiarios, tal sistema alcanzó con el tiempo a convertirse en un elemento hegemónico y casi mitológico dentro de esa sociedad, hasta las últimas décadas en que la crisis del Estado lo está arrastrando consigo. Esto convierte al estudio de las paradójicas alternativas de su emergencia en una cuestión doblemente importante. ${ }^{4}$

\section{Precursores y otros actores educativos}

La consolidación de un sistema educativo elemental público en la Argentina de la segunda mitad del siglo XIX se dio en un contexto social y económico marcado por la incorporación del país de una manera importante al mercado mundial como proveedor de materias primas. El crecimiento económico provocado por ese proceso de expansión "hacia afuera" fue sin duda notable y tuvo importantes consecuencias sociales entre las que se destacaron la llegada al país de un número importante de inmigrantes, y un proceso muy marcado de urbanización. Se estima que un total de 7.000 .000 de inmigrantes arribaron al Río de la Plata entre 1869 y 1914, de los que permanecieron de manera estable $3.500 .000 .{ }^{5}$ Como se trata de una cuestión suficientemente abordada, me limitaré a ofrecer sólo algunos datos útiles para mostrar la inmensa tarea que tenía por delante el estado naciente en la búsqueda de una cierta homogeneidad cultural entre la

4 Importantes obras de referencia sobre la historia de la educación en Argentina son las siguientes: Alliaud, Andrea: Los maestros y su historia: los orígenes del magisterio argentino, Buenos Aires, 1993, 2 vol; Ascolani, Adrián (compilador): La educación en Argentina , Rosario 1999; Cucuzza, Héctor (compilador): La historia de la educación en debate, Buenos Aires 1996; Manganiello Ethel: Historia de la educación argentina. Periodización generacional, Buenos Aires 1980; Newland, Carlos: Buenos Aires no es Pampa. La educación elemental porteña 1810-1860, Buenos Aires 1992; Puigross Adriana (directora): Historia de la educación argentina, Buenos Aires, 1991, 5 vol; Ramos, Juan: Historia de la instrucción primaria en la República Argentina, Buenos Aires, 1910; Tedesco, Juan Carlos: Educación y Sociedad en Argentina, Buenos Aires 1986; Solari, Manuel: Historia de la Educación Argentina, Buenos Aires, 1949; Spalding, Hobart: "Education in Argentina, 1890-1914. The limits of oligarchical reform", Journal of Comparative Studies, 1981; Weimberg, Gregorio: Modelos educativos en América Latina, Buenos Aires 1984.

5 Argentina: Primer Censo Nacional, 1869, Buenos Aires 1872; Argentina: Segundo censo nacional, 1895, Buenos Aires, 1898; Argentina: Tercer Censo Nacional, 1914, 5 vols. Buenos Aires 1915-1917. 
población. En 1885, por ejemplo el $45 \%$ de la población de la ciudad de Buenos Aires había nacido fuera del país. A su vez, una encuesta realizada en 1914 entre escolares mostraba que sólo un 12\% tenían padre y madre argentinos. ${ }^{6}$

A la caída de Rosas en 1852, buena parte de las elites político intelectuales que lo sucedieron concibieron la difusión masiva de la educación como un instrumento eficaz de cambio social y de "progreso". En este sentido se hacían eco de un optimismo pedagógico muy propio del pensamiento del siglo XIX. Sin embargo dicho optimismo, cuyo ejemplo paradigmático es la figura de Domingo Faustino Sarmiento, no fue absoluto. Pensadores de la talla de Alberdi, inspirador de la Constitución de 1852, se mostraban pesimistas con respecto al papel transformador de la educación. Creían fundamentalmente en la capacidad transformadora y casi mecánica de unos planes inmigratorios y de colonización, que junto al cambio racial introducirían de inmediato un "espíritu de industria" propio de los países del norte de Europa. Se colocaban en ese sentido en el polo opuesto del pensamiento de Sarmiento que, si bien contenía también una fuerte faceta utilitarista, enfatizaba bastante más el papel político de la educación debido sobre todo a su afán de transformar de manera rápida al habitante de las pampas en un ciudadano activo según el modelo anglosajón. Esta disyuntiva entre utilitarismo y sentido político de la educación se iba a mantener como una constante a lo largo de todo el siglo. ${ }^{7}$

Sin embargo el fracaso del sistema de colonización, que quedó limitado sólo a algunas regiones, y sobre todo la gran distancia existente entre las expectativas previas y el origen étnico y regional de los inmigrantes que efectivamente arribaron al Río de la Plata, convirtieron en letra muerta muchos de esos planes educativos y de transformación social. Otros en cambio fueron seriamente reorientados, con lo que perdieron buena parte de su sentido original. ${ }^{8}$

6 Recchini de Lattes, Zulma y Lattes, Alfredo: La población argentina, 1857-1924, Buenos Aires 1975 ; Finkel, Sara: "La clase media como beneficiaria de la expansión del sistema educacional argentino, 1880-1930", en: Labarca, Guillermo, Vasconi, Tomás; Finkel, Sara, y Recca, Inés: La educación burguesa, México, 1977, págs. 93-136.

7 Weimberg: Modelos educativos; Tedesco: Educación

8 La distancia entre los primeros planes de educación popular en los que Sarmiento había puesto gran parte de sus expectativas transformadoras y el modelo educativo que se consolidó de manera efectiva con posterioridad fue realmente enorme. Al respecto puede consultarse: Tedesco: Educación; 
Entre 1852 y 1880, periodo histórico conocido como de la "consolidación nacional", se destacaron los cambios estructurales que tuvieron lugar en la década de 1870 en los distintos niveles de la enseñanza. A la cabeza de esos cambios se situaron los tres primeros presidentes del país, Mitre, Sarmiento y Avellaneda, quienes al mando de un estado nacional todavía débil, mantuvieron a la educación entre sus principales inquietudes intelectuales y de gestión gubernativa. También participó en tales cambios un grupo de antiguos emigrados de la época rosista, pertenecientes en su mayoría a la llamada generación intelectual de 1837 y conocidos casi todos ellos por su liberalismo de corte radical, como Juan María Gutiérrez rector de la Universidad de Buenos Aires. Este, tuvo una gran influencia sobre un conjunto de jóvenes liberales que clamaba cada vez con más fuerzas por la plena autonomía educativa, lo que por entonces planteaba, al igual que había sucedido años antes en Colombia y México, una difícil relación con los intentos todavía tenues de imponer una educación elemental obligatoria. ${ }^{9}$ Sin embargo, con el paso de los años y adaptándose a los cambios ideológicos de la época algunos de ellos, como Zeballos y Ramos Mejía participarían de una manera importante en la consolidación de un sistema educativo fuertemente centralizado impulsado desde el gobierno.

Fue gracias al énfasis puesto por Sarmiento en la necesidad de dar prioridad a la instrucción elemental que el debate educativo pudo abarcar otros temas y no referirse sólo al reducido ámbito de las elites e incipientes clases medias. Debido sobre todo a su iniciativa se adoptaron importantes medidas que mostraban una apuesta por cambios bastante radicales en la organización educativa tradicional, casi inexistente. Admiraba Sarmiento el sistema educativo aplicado en varias regiones de los Estados Unidos y el pensamiento de Horace Mann. Fue esa admiración la que lo indujo a contratar a un número importante de maestras estadounidenses para que difundieran sus ideas y sobre todo el espíritu democrático y de participación civil que Sarmiento consideraba propio de aquel país. En la misma línea creó el primer centro de formación de docentes, la Escuela Normal de Paraná e impulsó la creación de asociaciones "de amigos de la educación" y las bibliotecas populares. Una importante iniciativa suya fue el reglamento general de escuelas que otorgaba a unos consejos escolares

9 Weimberg: Modelos educativos; Halperin Donghi, Tulio: Historia de la Universidad de Buenos Aires, Buenos Aires 1962. 
de distrito, también de carácter electivo, la supervisión de las actividades de las escuelas. ${ }^{10}$

Además de los políticos e intelectuales que han sido mencionados otros actores colectivos participaron en la época en la creación de un campo cultural educativo. Ya en la década de 1850 comenzaron a proliferar de forma espontánea sociedades populares de educación entre las que predominaron las creadas por las colectividades españolas e italianas que en buena medida intentaban paliar la precariedad del sistema de educación público.

La intervención de los inmigrantes en la educación fue muy distinta, sin embargo, al modelo imaginado por los intelectuales de la época, al cual se acercaban más las maestras norteamericanas. Al fundar escuelas y asociaciones educativas las colectividades extranjeras, en particular la colectividad italiana y algunas minoritarias como la galesa, intentaron controlar la reproducción de su cultura nativa. Como las reformas de la época tenían básicamente un contenido cosmopolita, sus impulsores no podían dejar de mostrarse sorprendidos e incluso defraudados por la aparición en aquellas asociaciones de los mismos rasgos particularistas que habían pretendido eliminar del ámbito local por medio de la inmigración. Con la realización del Congreso pedagógico italiano de la Provincia de Buenos Aires en 1881, que mereció la dura crítica de Sarmiento, se hacía evidente el comienzo de una nueva época. ${ }^{11}$

10 Las ideas educativas que Sarmiento persiguió durante toda su vida fueron esbozadas en "Educación Popular", ensayo publicado como libro en 1949 y que incluye sus estudios de los sistemas docentes de Europa y Estados Unidos, países a los que viajó financiado por el gobierno chileno. Se suponía que esos estudios sentarían la base para una reforma del sistema educativo de ese país, lo que no fue posible entonces. Sin embargo, si serían adaptados a la Argentina un cuarto de siglo más tarde. Sarmiento, Domingo Faustino: Educación Popular, Buenos Aires 1915. Sobre la escuela normal de Paraná véase: Carli, Sandra: "Escenario educativo (1883-1930)", Cuadernos, Facultad de Ciencias de la Educación, Entre Ríos, Santa Fe 1995. El reglamento general de escuelas fue promulgado durante el gobierno del presidente Nicolás Avellaneda por la Comisión Nacional de educación presidida entonces por Sarmiento.

11 Las críticas de Sarmiento a la actividad educativa de la colectividad italiana pueden consultarse en: "Las escuelas italianas: su inutilidad" y "Las escuelas italianas", en Sarmiento, Domingo Faustino: La condición del extranjero en América, Buenos Aires 1915, artículos publicados originalmente en El Nacional el 13 y 14 de enero de 1881; Sobre la problemática de la inmigración italiana, su incorporación al medio social argentino y la cuestión educativa consúltese: Favero, Luigi: "Las escuelas de las sociedades italianas en Argentina" en Rosoli, Gianfausto y Devoto Fernando: La inmigración italiana en la Argentina, Buenos Aires 1985, págs. 165-208; Halperin Donghi, Tulio: “¿Para que la inmigración? Ideología y política inmigratoria en la Argentina (1810-1914)” en, Halperin Donghi, Tulio: El espejo de la Historia, Buenos Aires 1987 págs. 191-238 y "La integración de los inmigrantes italianos en Argentina. Un comentario", en Rosoli y Devoto: Inmigración italiana, págs. 87-93; Lilia Ana Bertoni: Patriotas, cosmopolitas y nacionalistas, Buenos Aires 2001. En especial el capítulo II, "La escuela y la formación de la nacionalidad, 1884-1890”, págs. 41-77 


\section{La consolidación del sistema}

El sistema público de educación elemental, inició su afianzamiento pleno en los años 80. Con la federalización de la ciudad de Buenos Aires y la cuestión del "orden nacional" prácticamente solucionadas el general Roca y sus ministros encararon con premura la plena institucionalización de la actividad educativa en todo el país. ${ }^{12}$

Para el nuevo gobierno la plena conformación de un sistema nacional de enseñanza diferenciado por niveles era algo fundamental. Consideraba imprescindible a su vez que el nivel primario tuviera un alcance y una uniformidad suficientes para garantizar una mínima homogeneidad cultural en una población en la que la presencia inmigratoria era cada vez más importante. Obviamente, tal homogeneidad pretendía lograrse a partir de la universalización de la propia visión del mundo de la elites gobernantes.

Un momento clave de tal proceso, casi diríamos fundacional, fue el año 1884 fecha de la promulgación de la ley 1420 de Educación Común. Esta ley tuvo como principal antecedente al congreso pedagógico sudamericano de 1882, convocado por el propio gobierno argentino y considerado un hito en el desarrollo educativo de la región. Aparte de los invitados de países vecinos, la mayoría de sus participantes estuvo compuesta por importantes intelectuales locales a los que se sumaron funcionarios educativos de distinto rango. Ambos grupos comenzaban así, bajo la sombra protectora del estado a definir de forma más orgánica una relación que con sus acuerdos y tensiones permanentes se convertiría en una típica característica del funcionamiento del sistema. ${ }^{13}$

Todos los congresistas eran conscientes de la mala situación de partida por lo que en forma prioritaria debatieron sobre infraestructura y formación docente. Sólo como tema secundario algunos advirtieron de la necesidad de otorgar homogeneidad cultural a la población por medio de una educación de características "nacionales". Los debates presentaron continuidades y rupturas frente al pensamiento educativo de los años pre-

12 Lobato, Mirta (directora): El progreso, la modernización y sus límites 1886-1916, Nueva Historia Argentina, Tomo V, Buenos Aires 2000; Botana, Natalio: El orden conservador, Buenos Aires 1977; Cortés Conde, Roberto y Gallo Ezequiel: Argentina: La República Conservadora, Buenos Aires 1972;

13 Weimberg, Gregorio (Estudio preliminar, selección y notas): Debate parlamentario sobre la ley 1420, Buenos Aires 1946; Cucuzza, Rubén: De Congreso a Congreso. Crónica del Primer Congreso Pedagógico Argentino, Buenos Aires 1986; Recalde Héctor: El Primer Congreso Pedagógico, 2 vols, Buenos Aires 1987. 
vios. Mientras muchos oradores insistían en la necesidad de mantener una fuerte autonomía de las instituciones educativas frente a la política y el gobierno, un profundo silencio se tejió alrededor de otras cuestiones que habían sido importantes hasta entonces como la participación popular en la dirección de las escuelas.

La Ley 1420 de Educación Común estableció la educación elemental, obligatoria, laica y gratuita para los niños comprendidos entre los seis y catorce años. Puede decirse que en términos generales la forma que finalmente adoptó esta ley fue el resultado de una pugna entre tres modelos alternativos de dirimir la relación entre el Estado y el sistema educativo. Primero: el impulsado por el gobierno y los intelectuales liberales que lo secundaban que planteaba una decisiva intervención estatal. Segundo: el de la Iglesia Católica que, sin negar la necesaria intervención del Estado, solicitaba mayores márgenes de autonomía para su proyecto educativo institucional y tercero: el de las asociaciones populares de educación, que abogaban por su independencia dentro de marcos generales más imprecisos. Triunfó con cierta comodidad la primera alternativa sostenida con firmeza por las elites liberales frente a la debilidad de la Iglesia que no alcanzó entonces a consolidar una alternativa sólida como la que desarrollaría ya entrado el siglo XX. Se trató sin embargo de un éxito con rasgos aparentemente paradójicos que en absoluto fueron exclusivos de la Argentina. Conviene recordar en ese sentido las reflexiones de Gregorio Weinberg y de Charles Hale acerca de cómo el liberalismo triunfante se negaba si mismo. ${ }^{14} \mathrm{Al}$ mismo tiempo comenzaba a plantearse en las cuestiones educativas el mismo dilema entre la república posible y la república verdadera, que tanto agobio produjo entre las elites intelectuales y gobernantes de la época. Paul Groussac, uno de los más brillantes intelectuales liberales, ya reclamaba entonces la necesidad de un centralismo educativo salvador que corrigiera los errores de una participación popular y un federalismo inexistentes en la práctica. ${ }^{15}$

14 Hale, Charles: "Ideas políticas y sociales en América Latina, 1870-1930" en Bethell, Leslie (ed): Historia de América Latina, vol. 8, Barcelona, 1991, págs. 1-64. Weimberg: Modelos educativos.

15 En la segunda sesión ordinaria del Congreso Paul Groussac leyó una ponencia que le fue encargada sobre el estado de la Educación. Allí sostenía que "En las cuatro administraciones que llevamos, la progresión centralista es patente y sigue la misma razón que la fuerza del edificio nacional." Para agregar a renglón seguido: "El centralismo salvador está por ahora en las cosas; poco importa que no esté en las palabras. Toda obra civilizadora lo robustece. ¿cuántas provincias han podido hacer un canal, un ferrocarril, un colegio, un buen edificio escolar,..sin el dinero, sin los planos, sin los empleados de la Nación?” citado en: Recalde: Primer Congreso, T 1, pág. 118. 
La ley 1420 marcó sin embargo sólo un comienzo. Un conjunto de amplias expectativas, como formar al ciudadano, al hombre de industria y lograr una mayor homogeneidad cultural entre la población presionaban sin rumbo preciso, desde hacía tiempo, en favor del desarrollo de una educación básica en todo el país. Para que esa educación básica cobrara vida era fundamental crear un aparato institucional que por un lado asegurara la efectiva difusión de los contenidos que se querían transmitir y por otro propiciara la uniformidad de los saberes y métodos que la hicieran posible. Tal empresa requería un complejo andamiaje que implicaba, a su vez, la transformación radical de la escuela pública y lo que era más importante aún: la constitución de un campo cultural educativo en el que esta escuela estuviera ubicada en su mismo centro. El Consejo Nacional de Educación, creado en 1881 y revalorizado por la ley 1420 , fue el organismo centralizador que impulsó ese proceso por lo que se lo puede considerar el actor educativo clave del periodo.

No tenía por delante el Consejo una tarea sencilla. Pero estaba arropado por la firme voluntad política de la elite gobernante que lo dotó de importantes fondos que oscilaron entre un 9 y un $12 \%$ del presupuesto anual del Estado, ubicó a su frente, con prerrogativas de ministros, a intelectuales de primera línea y de su máxima confianza y le otorgó una inusual autonomía para los cánones de la época. ${ }^{16}$

Al principio su tarea fue vacilante, como lo fue el pleno apoyo estatal, pero su posición logró afianzarse plenamente hacia fines de los años 80 , cuando la transmisión de unos sentimientos de nacionalidad comenzó a ser visualizada como imprescindible, ante la alarma que producían la lealtad a otras naciones e incluso el surgimiento de movimientos monárquicos entre unos inmigrantes que comenzaban a arribar al país en cantidades nunca vistas. Los fines homogeneizadores e incluso igualadores de la educación se convertían ahora sí en objetivo político prioritario. Paralelamente, mientras

16 El presidente del Consejo Nacional de Educación gozaba del rango de ministro y se pretendía que tuviera plena autonomía y estabilidad. Tanto fue así que sus respectivas gestiones fueron independientes de los cambios de gobierno y, en general, más largas que los mandatos de los ministros de Educación. Tedesco, Juan Carlos: Educación; Importantes cuestiones sobre la centralización educativa son abordadas en: De Luca, Alejandro: "Consejos Escolares de Distrito: subordinación o participación popular" y Marengo, Roberto: "Estructuración y consolidación del poder normalizador: el Consejo Nacional de Educación, en Puigross, Adriana (dirección), Historia de la Educación Argentina, Sociedad Civil y Estado en los orígenes del sistema educativo argentino, Buenos Aires, 1991, Tomo II, págs. 47-69 y 70-175. En el trabajo de Marengo puede consultarse también una enumeración de miembros de las distintas gestiones del Consejo Nacional de Educación, de las comisiones asesoras, como así también de los miembros de los respectivos Consejos Escolares de distrito y los políticos e intelectuales notables que formaron parte de ellas en los distintos periodos. 
declaraba la supremacía de la escuela pública el CNE seguía sin pausa su empresa de expansión y obtención de hegemonía educativa, cuyo primer paso era hacer cumplir de manera efectiva las disposiciones de la ley $1420 .^{17}$

En efecto, el primer y gran objetivo del Consejo fue obtener el pleno cumplimiento de la obligatoriedad escolar que marcaba la ley, lo que implicaba luchar contra la aprensión y la indiferencia de los padres, pero también contra la arraigada costumbre de educar en el seno del hogar. Apeló para ello al uso de la fuerza pública y a la imposición de multas, pero sobre todo intentó persuadir con campañas masivas de matriculación, reparto de alimentos o la atención sanitaria gratuita. ${ }^{18}$ Cumplieron también un papel de importancia los nuevos edificios escolares que empezaron a construirse por entonces con gran despliegue de medios, los llamados "templos del saber", diseñados para ejercer un importante impacto simbólico sobre la población. ${ }^{19}$

Fue importante para la consolidación del Consejo el impulso que le brindó un conjunto de intelectuales que compartían los temores de muchos otros miembros de la elite por las posibles consecuencias políticas, sociales e incluso institucionales de la fuerte, y constante, lealtad mostrada por muchos inmigrantes hacia sus países de origen. Algunos de ellos, como Estanislao Zeballos, activo participante en muchas cuestiones educativas, presidente de la Cámara de Diputados y, a su vez, futuro ministro a principios del siglo XX, se mostraron en la segunda mitad de la década de 1880 bastante impacientes por esas circunstancias y criticaron fuertemente a una escuela y un sistema educativo que estaban entonces todavía lejos de alcanzar el público amplio que pretendían. ${ }^{20} \mathrm{Al}$ redefinir la vieja idea de Sarmiento de "educar al soberano" dentro de unos marcos de promoción de la nacionalidad, estos intelectuales observaban también cómo la consolidación de un sistema educativo con esas características les permitía definir un perfil y un espacio simbólico propio más allá de la política. Sin embargo

17 Bertoni: Patriotas, cosmopolitas

18 Esto formaba parte también de una importante estrategia elaborada por el Consejo para hacer que las escuelas públicas fueran no sólo preferibles sin también mejores. Para ello era imprescindible paliar sus obvias deficiencias. En tal sentido fue de suma importancia el rol jugado por los aspectos simbólicos derivados del tipo de elección arquitectónica que se realizaba para realzar el empuje escolar. Bertoni: Patriotas, cosmopolitas.

19 Schmidt, Claudia: "De la escuela palacio al "Templo del Saber", Edificios para la educación moderna", Entrepasados, Año IX n. ${ }^{\circ}$ 18/19, Buenos Aires, fines de 2000.

20 Consejo Escolar del XI Distrito, "Informe del presidente E. Zeballos y del secretario Miguel Auli", 7 de enero de 1888, El Monitor de la Educación Común, tomo VII, n. ${ }^{\circ}$ 128, marzo de 1888, p.349. Consúltese también Bertoni: Patriotas, cosmopolitas, págs. 41-77 
conviene recordar, como lo hace Tulio Halperin Donghi, que se estaba muy lejos todavía de la configuración de lo que hoy se conoce como un "campo intelectual". Fue a partir de entonces que, entre 1887 y 1892 para ser más precisos, intelectuales de renombre y otros más jóvenes con ansias y conexiones sociales para serlo, desembarcaron en las diversas comisiones asesoras creadas por el Consejo, como las de didáctica, reformas de programas de estudio y elección de textos escolares. ${ }^{21}$

Otra cuestión fundamental para el Consejo fue la creación de instrumentos institucionales que le permitieran tener un efectivo control sobre la totalidad del sistema, es decir tanto sobre las escuelas públicas como sobre las privadas, que representaban aproximadamente un $30 \%$ del total. Tal objetivo se planteó primero a través de la reformulación del sistema y los mecanismos de inspección vigentes que estaban a cargo de los Consejos Escolares de Distrito, elegidos en comicios populares entre los notables locales. Los conflictos que estos cambios produjeron fueron zanjados finalmente mediante la creación en 1889 de un cuerpo técnico centralizado de inspectores, dependiente en forma exclusiva de la estructura interna del Consejo, lo que motivó un serio replanteo de su relación con los consejos escolares y de toda la orientación educativa.

Como resultado los inspectores se convirtieron en la figura clave de un sistema con una tendencia cada vez más fuerte a la centralización, organizado burocráticamente y estricto, tanto con los consejos de distrito, como con las escuelas de colectividades extranjeras. Buena prueba de ello fue que a partir de entonces la casi totalidad de las decisiones del Consejo fueron adoptadas sobre la base de la opinión de aquella nueva elite de inspectores. Pero ¿Quiénes eran y de donde salían los miembros de esta nueva elite burocrática? Para responder a estas preguntas hay que adentrarse en la estructura profesional del sistema educativo.

En tal sentido conviene resaltar que el nuevo marco educativo que se estaba conformando, en el que eran cada vez más importantes el fomento del sentimiento de nacionalidad, el centralismo en la toma de decisiones,

21 Halperin Donghi, Tulio: "Intelectuales en la primera democracia argentina", en Plotkin, Mariano y González Leandri, Ricardo: Localismo y globalización. Aportes para una historia de los intelectuales en América Latina, Madrid, 2001. Sobre la participación de intelectuales en las comisiones de planes de estudio, consejos escolares y de selección de textos puede consultarse los listados reseñados por Roberto Marengo a partir de la información publicada en el Monitor de la Educación Común. Por ejemplo, en 1887 puede observarse la participación en distintas comisiones de textos escolares de importantes intelectuales y profesionales como Paul Groussac, Norberto Piñero, Calixto Oyuela, Enrique Navarro Viola, Lucio V. López, Luis A. Huergo, Eduardo Holmberg y José María Ramos. Mejía Marengo: "Poder normalizador". 
y la minuciosa regulación de las atribuciones y los requisitos credencialistas, tuvo, como era previsible, fundamentales consecuencias sobre la estructura interna de la carrera docente en sus distintos estamentos. ${ }^{22}$

\section{Profesión docente y paradojas de la elite normalista}

Los docentes de la época, a la vez burocracia estatal y profesión en vías de consolidarse, constituyeron un conjunto jerarquizado y muy heterogéneo.

Sus capas superiores, compuestas por inspectores y funcionarios de alto rango, formaban un todo indisociable con la corriente pedagógica conocida como normalismo, que sentó buena parte de las bases ideológicas del sistema educativo y alcanzó a conformar una sólida subcultura de notable influencia durante el último cuarto del siglo XIX y el XX.

El movimiento normalista tuvo su origen en la Escuela Normal de Paraná, a la que ya he hecho referencia, que por sus características, metodología y personal directivo, fue considerada como un trasplante de Boston a la Argentina. ${ }^{23}$

22 A través de sanción de nuevo reglamento sobre inspección nacional en provincias El CNE comenzó a extender su influencia al resto del país. Se nombró un inspector en cada provincia para controlar inversión de fondo escolar y para mantener un mismo sistema de enseñanza en todas partes y eliminar los desequilibrios. Comenzó así la consolidación de un cuerpo técnico centralizado. Hasta entonces el Cuerpo de Inspectores, que había sido creado por la ley de subvenciones nacionales de 1871 había funcionado sólo de una manera precaria. Para realizar esa reforma se siguió sobre todo la opinión de quienes desde el interior del cuerpo docente ansiaban una "inspección permanente e independiente de toda otra autoridad que no fuera el CNE", con atribuciones claramente determinadas y responsabilidades definidas. Con la promulgación del reglamento de Inspección de 1889, que implicó la consolidación de un cuerpo autónomo de inspectores se replanteó la relación del CNE y los consejos escolares a los que los inspectores estaban hasta entonces estrechamente vinculados. Consejo Nacional de Educación: Circular a los inspectores nacionales de las provincias con motivo del Reglamento recientemente sancionado, Buenos Aires, agosto de 1889, El Monitor de la Educación Común, tomo IX, n. ${ }^{\circ}$ 163, agosto de 1889, págs. 143 y 144. Consúltese Marengo: “Estructuración y consolidación del poder normalizador” pág. 83.

23 La escuela Normal de Paraná fue fundada por Sarmiento en 1870 sobre la base del colegio de Paraná y se convirtió en expresión emblemática de sus ideas de transformación educativa. Su primer director fue el pedagogo norteamericano G.A. Stearns que elaboró un plan de estudios basado en la experiencia de algunos estados de la unión y previó una escuela normal y una escuela modelo de aplicación de cuatro y seis años de estudios respectivamente, que actuarían a su vez como garantía de formación de maestros y como modelo "normalizador" de la educación primaria. Carli: "Escenario educativo". Referencias explícitas a la idea de que la Escuela de Paraná fue un trasplante de Boston en: Ministerio de Justicia; Culto e Intrucción Pública: Memoria correspondiente al ejercicio del año 1892, Buenos Aires 1893, pág. 20; Con respecto a la formación de maestros de menor calidad, desde la propia elite educativa se afirmaba en 1898 que "Un maestro formado en mejores condiciones resultaría demasiado caro; pero conviene no perder de vista que así se los necesita en una categoría de escuelas y no en todas" Ministerio de Justicia; Culto e Intrucción Pública: Memoria correspondiente al ejercicio 1898, Buenos Aires 1999. 
Los licenciados de la escuela de Paraná, que en casos muy contados ejercieron de manera efectiva como maestros de escuela, adquirieron de forma inmediata la seguridad de pertenecer a una elite cultural y burocrática con una importante misión que cumplir. Las palabras de Sarmiento eran para ellos un mandato y se sentían fuertemente inmersos en esa pugna entre civilización y barbarie que aquel tan gráficamente había descrito y cuyo principal enemigo interno era la ignorancia.

Se trató, sin embargo, de una elite peculiar conformada por becarios jóvenes de escasos recursos a los que con el tiempo se fue aupando a los altos cargos de la estructura docente. El gobierno aplicaba de tal manera una estrategia clara de creación de un personal especializado, complementario al que se formaba en los colegios nacionales, cuya orientación era fundamentalmente producir doctores hábiles para la política y el gobierno. Se intentaba dar forma a una capa de intelectuales y funcionarios subalternos que ocuparan papeles claves en la reproducción cultural. Puede decirse que en términos generales esa empresa se vio coronada por el éxito y que se logró paliar con ello una de las deficiencias más notorias del sistema educativo en sus comienzos. La experiencia de la Escuela de Paraná fue prontamente emulada y se crearon a posteriori un conjunto de escuelas con los mismos objetivos generales. Sin embargo, la premura de los gobiernos, sus deseos de economizar y el énfasis en producir maestros "de distinta categoría y calidad", según el destinatario social, determinaron que por mucho tiempo las titulaciones de la Escuela de Paraná fueran ampliamente preferidas por aquellos con aspiraciones de acceder a la elite educativa. Esta diferenciación dio lugar a importantes tensiones de nuevo cuño que habrían de tener importantes consecuencias sobre el destino de la estructura educativa y de la profesión docente..$^{24}$

A partir de la década de 1880 al movimiento normalista le tocó jugar un papel que contenía rasgos contradictorios que convirtieron su "misión" educativa en una cuestión azarosa y compleja. Herederos de las convicciones transformadoras de Sarmiento y de la pragmática educación norteamericana, los normalistas pasaron a ocupar el centro de gravedad de la educación pública y se transformaron en impulsores privilegiados de la nacionalidad, dentro de unos marcos educativos que siguieron poco las orientaciones fundamentales del ex presidente. Formaron parte entonces de

24 Alliaud, Adriana, Los maestros y su historia: los orígenes del magisterio argentino, 2 vols., Buenos Aires 1993. 
un sistema bastante más rígido y centralizado del que habían previsto sus primeros impulsores cuya implementación coincidió a su vez con cambios importantes en la valoración del proceso inmigratorio por parte de las elites gobernantes. De "educadores" deseados, en cuanto impulsores de aquella "educación de las cosas" tan ensalzada por Alberdi, los inmigrantes pasaron a ser considerados como sujetos que necesariamente debían ser categorizados y transformados. ${ }^{25}$

El movimiento normalista pudo encarar aquellas actividades centrales debido en buena medida a su adhesión al ideario positivista del que la escuela de Paraná fue uno de los más importantes difusores, gracias a José María Torres y, sobre todo, a Pedro Scalabrini, introductor del pensamiento de Comte en la Argentina. Puede decirse en tal sentido que su creciente influencia formó parte del mismo proceso ideológico e institucional por el cual el liberalismo de corte radical, abrazado con tanto ahínco por una parte decisiva de los intelectuales, sobre todo porteños, se trocó hacia la década de 1880 en una ideología organicista, bastante más apegada a los avatares del aparato estatal. ${ }^{26}$

Sin embargo esa adhesión al positivismo por parte de los normalistas no fue en absoluto homogénea y mostró un grado de eclecticismo bastante mayor del que en general se le ha atribuido. Además, la adaptación de esta ideología a la práctica educativa concreta mostró en muchos aspectos escasa solidez y coherencia, sobre todo debido a la manera esquemática en que era difundida hacia las capas más inferiores de la profesión.

Esa postura ideológica se vio complementada a su vez por un fuerte afán por liderar la construcción profesional de la docencia. Bajo su dirección el conjunto del cuerpo docente hizo importantes esfuerzos en la década de 1880 para alcanzar el monopolio de una actividad que estaba muy lejos de darse en la práctica. Con tal propósito surgieron asociaciones que trataron de obtener como primer paso el mejoramiento de las condiciones de todos los estamentos docentes. Se destacó en esa tarea la Asociación Nacional de Educación fundada en 1886 gracias al impulso del Centro Unión Normalista de la Capital Federal. Su ejemplo fue imitado en forma inmediata por colectividades docentes de otras regiones y ciudades que fundaron asociaciones similares en casi todas las capitales de provincia.

25 Tedesco: Educación.

26 Tedesco: Educación; Tedesco, Juan Carlos "La instancia educativa", en Biaggini, Hugo (compilador): Movimiento positivista argentino, Buenos Aires, 1985, págs. 333-361; Solari, Manuel, Historia de la educación , págs. 223-257. 
El empuje de esas asociaciones, que pueden ser consideradas también como otro de los subproductos de la ley 1420, fue muy grande. Gracias a su actividad se produjo hacia fines de la década de 1880 un cierto auge, no sólo asociativo sino también cultural del campo docente en formación. Este se basó en el emprendimiento de acciones colectivas tendentes a incrementar y controlar los espacios de difusión y producción de conocimientos pedagógicos. Para ello las nuevas asociaciones organizaron conferencias y crearon bibliotecas, que muy pronto el Consejo Nacional de Educación se vio en la necesidad de reglamentar. Pero el producto más destacado de su labor fue la aparición de revistas especializadas que significaron un notable incremento de la producción intelectual orientada hacia la pedagogía. Como dato ilustrativo puede mencionarse que entre 1886 y 1888 se registró la existencia de 16 revistas editadas por distintas asociaciones de maestros o escuelas normales. ${ }^{27}$

Un par de cuestiones claves teñían casi todos los artículos, notas y editoriales publicados en esas revistas y significaron un indicio claro de los afanes profesionalizadores de los docentes de la época. La primera era considerar al cuerpo de maestros diplomados como el único con la suficiente legitimidad, dada su especialización, para producir y difundir prácticas y saberes pedagógicos. La segunda era la promoción de la ciencia pedagógica, a la que se deseaba dotar de un alto prestigio social. Esa promoción iba acompañada, en forma lógica, por la exigencia de unas remuneraciones para sus cultores, acordes con la importancia social de esa tarea.

$\mathrm{Al}$ encontrarse en pleno proceso de pugna por la construcción profesional las asociaciones docentes, y las revistas que actuaban como sus voceros, trabajaron en forma permanente por el perfeccionamiento intelectual y económico de sus miembros. Buscaban por tanto los docentes definir sus incumbencias y precisar cuales eran los atributos y requisitos para el ejercicio legítimo de la actividad que consideraban propia. Al mismo tiempo reivindicaban para si el derecho de ocupar, en tanto especialistas, los puestos de mayor jerarquía en la estructura educativa. ${ }^{28}$

27 Alliaud: Maestros; Marengo: "Poder normalizador". Se destacaron las asociaciones siguientes: Asociación de maestros, fundada en 1885 y presidida por J. M. Larsen; el centro Unión Normalista , fundada en 1886 y presidida por Juan Trufó y la Asociación de Enseñanza de Santa Fe. En cuanto a las publicaciones, además del Monitor de la Educación Común, de carácter oficial, fueron importantes por las personas que estuvieron a su cargo : "La Educación", redactada por Zubiaur, M. Sarsfield Escobar y C. Vergara, "La Enseñanza", de J. Trufó y P. Pizzurno y la "Revista Pedagógica Argentina de F. Guerrini.

28 Alliaud: Maestros 
De la misma forma que otros grupos profesionales en formación los docentes solicitaron al Estado, de cuyo aparato formaban parte en una importante proporción, un control más estricto de los distintos aspectos de su actividad, en especial los referidos a las credenciales, y la salvaguardia de algunos derechos que consideraban adquiridos. En tal sentido fueron muy frecuentes las quejas con respecto a la actividad de los llamados "maestros libres", sin título habilitante. También reclamaban de los poderes públicos una fuerte centralización en la toma de decisiones que los implicaban. En este caso, sin embargo, la puesta en práctica de tales iniciativas iba a recibir lecturas bastante distintas por parte de los múltiples estamentos del cuerpo docente. Todas las expectativas y solicitudes mencionadas llevaban implícito, además, el establecimiento de la especificidad del saber pedagógico y la definición de sus reglas y métodos

La actividad de las asociaciones y órganos de prensa señalados y el movimiento en favor de la profesionalización y la consolidación del campo de la pedagogía, encabezados por miembros de la elite intelectual normalista, apuntaban a una serie de reivindicaciones que respondían a intereses compartidos por todos los estratos del colectivo docente. Había sin duda una importante zona de convergencia de intereses, por más que algún sector pudiera beneficiarse más que otros en casos determinados. Así, por ejemplo, la solicitud de mayor regulación y control estatal y el ataque a los "maestros libres" interesaba al conjunto de los docentes, pero es cierto que afectaba más a aquellos con capacidad y relaciones suficientes para erigirse en inspectores. ${ }^{29}$

Sin embargo, resulta también evidente que el logro de muchos de esos objetivos de conjunto se vieron seriamente dificultados por la incapacidad de esos mismos sectores para alcanzar un consenso mínimo con respecto a los límites y al papel, científico o artístico, que debía atribuirse a la pedagogía como disciplina y también por su desigual posicionamiento dentro del sistema educativo.

En buena medida esa falta de consenso y la consolidación de fuertes diferencias de distinta índole (de formación, entrenamiento y jerárquicas), en el seno del cuerpo docente, causas de su futura debilidad comparativa

29 Conviene aclarar, sin embargo, que la pugna contra los maestros libres fue sumamente difícil y estuvo bastante lejos durante este periodo de saldarse con una victoria a favor de los "titulados". La memoria del Ministerio de Educación de 1892 señalaba que de 7054 maestros a cargo de la instrucción primaria, sólo 1704 habían pasado por los centros de formación de maestros, es decir que 5350 dictaban la enseñanza sin título habilitante. Ministerio de Justicia; Culto e Instrucción Pública: Memoria correspondiente al año 1892, Buenos aires 1893, págs. 536-537. 
con algunos otros grupos profesionales, se debió en una medida importante al propio carácter ambiguo y en ocasiones contradictorio de la elite normalista situada en su cúspide. Esa ambigüedad, motivada sobre todo por su posición de red intelectual subordinada, fue notoria tanto en el plano de la estructura organizativa y profesional de los docentes como en sus facetas ideológica y académica. De más está decir que ambos planos estuvieron imbricados de forma íntima.

Existen importantes indicios acerca de la forma en que ese proceso de diferenciación interna se fue ahondando y cristalizando. En primer término debe apuntarse el hecho de que los esfuerzos por que se considerara al saber pedagógico, y a sus cultores y difusores, como de alto valor social, vieron surgir a su lado, y con igual fuerza, una serie de actitudes que tendieron a limitar los posibles beneficios a un reducido grupo de elegidos.

Las causas de ese movimiento, originado en las capas más encumbradas del funcionariado educativo, con amplia presencia normalista, que entraba en contradicción con los profesados "intereses generales" de los docentes, obedecen a una compleja trama de motivos. Entre ellos se situaba en primer lugar la necesidad que existía en la época de jerarquizar determinado tipo de funciones, saberes y prácticas, como consecuencia del propio crecimiento y diversificación del aparato educativo. En segundo término se ubicaron los gestos que los grupos en ascenso en la estructura educativa realizaban para valorizar y "clausurar" sus respectivas posiciones adquiridas, con las consecuentes secuelas "desprofesionalizadoras" sobre el resto ${ }^{30}$ En términos más amplios puede decirse que la tendencia al ahondamiento de la heterogeneidad y las desigualdades (de posición pero también de formación) dentro del colectivo docente obedeció, sobre todo, a la necesidad de estructurar un sistema educativo elemental generalizado con recursos escasos. Conviene aclarar, sin embargo, que si bien en este caso los recursos destinados a la educación elemental fueron importantes dentro

30 Utilizo el término "clausura" en el sentido que lo sugiere la corriente de estudios que sofistica el tradicional concepto weberiano de "monopolio". Consúltese: Murphy, Raymond: Social Closure. The theory of Monopolization and Exclusion, Oxford 1988; Collins, Randall: "Market Closure and the Conflict Theory of the Professions", en Burrage, MIchael y Torstendahl Rolf: Professiones in Theory and History. Rethinking the Study of the Professions, London 1990.

La existencia de diferencias crecientes dentro del cuerpo docente no implica que estas no hayan existido desde siempre. La generalidad de la cúpula normalista provenía de familias de escasos recursos económicos (aunque no humildes). Un elemento clave a tener en cuenta en la consolidación de esas diferencias es en este caso la diferente capacidad de acceso por parte de los distintos actores educativos a recursos materiales y simbólicos, sin duda limitados y, sobre todo, a las redes de influencia política 
del presupuesto de gastos del Estado, era evidente que se partía de niveles educativos realmente muy bajos. Además, incidió el fuerte deseo político de mantener el crecimiento del sistema a la par del de la población, que era sin duda notable.

Estas cuestiones deben ser observadas con un poco más de detenimiento. Una vez encumbrados en la estructura docente estatal luego de la promulgación de la ley 1420 y sobre todo de la reformulación del sistema de inspección en 1889 los normalistas adoptaron una actitud cada vez más oscilante frente al resto del cuerpo docente. Por una parte las revistas que dirigían e impulsaban mantuvieron un discurso corporativo y muchas veces solidario e inclusivo. Sin embargo ese discurso fue variando de a poco. $\mathrm{Si}$ bien en términos generales mantuvo su énfasis en la idea de "misión" y en la abnegación del maestro que luchaba contra la ignorancia, cada vez otorgó mayor espacio a las objeciones a su indiferencia y a sus escasos conocimientos, que muchas veces actuaban casi exclusivamente como mecanismos de exclusión. Dado que los normalistas ubicados en la cúspide burocrática no se veían sometidos a constricciones grupales ni corporativas, podían criticar con dureza y en buena medida incluso intentar "desjerarquizar" o, más precisamente, limitar los intentos de jerarquización de otros sectores del cuerpo profesional docente del que ellos mismos formaban parte. Comenzó por lo tanto un paralelo desvanecimiento de las invocaciones solidarias al conjunto de la profesión.

Si comparamos la trayectoria del cuerpo docente con la de otras profesiones en formación en la época como los médicos, por ejemplo, puede observarse una sensible diferencia. Si en este último colectivo las críticas por parte de las elites a otros estamentos inferiores, a los que denostaban como "empíricos", fueron también fuertes durante un tiempo, a medida que la institución académica se renovó y consolidó, esas críticas "internas" desaparecieron o al menos dejaron de tener un carácter público. De tal forma los distintos sectores médicos, salvo los homeópatas al los que se consideraba fuera del sistema, cerraron filas en torno a una institución que en alguna medida los amparaba a todos y dirimían sus diferencias, que las había, de una manera casi secreta. ${ }^{31}$

En el caso de los docentes la cuestión fue bastante distinta..$^{32}$ Además de los hechos altamente significativos de que para esa época no lograron

31 González Leandri, Ricardo: Curar, persuadir, gobernar. La construcción histórica de la profesión médica en Buenos Aires, Madrid, 1999.

32 Alliaud: Maestros; 
consolidar una institución universitaria y de que las pugnas en torno al carácter "artístico" o "científico" fueron más enconadas, influyó también la cuestión de que las críticas a los estamentos subordinados $-\mathrm{o}$ a subordinar- y los gestos de diferenciación por parte de los normalistas fueron más necesarios y permanentes. Tanto por motivos internos al propio cuerpo docente, como externos, en los que sin duda influyó la competencia con "la" elite intelectual del momento, nos encontramos en la cúspide docente con un grupo mucho más débil y, por tanto, también más vulnerable..$^{33}$

Por otra parte, los normalistas cada vez más se consideraban a si mismos como un estamento "científico" y sobre todo intelectual bastante independiente del resto de los docentes. Al mismo tiempo, como miembros de la alta burocracia educativa estaban más atentos a los objetivos del Estado que a los del complejo y heterogéneo cuerpo con aspiraciones profesionales al que también pertenecían. Para el logro de su objetivo de convertirse en una elite intelectual situado en el pleno corazón del aparato del Estado resultaban sumamente útiles aquellos gestos y críticas que tendían a arrinconar al resto de los docentes, en un papel rutinario, fundamentalmente ritual y sobre todo, empírico. Las maestras de escuela, el último eslabón de la cadena educativa se vieron sometidas por tanto a un complejo y contradictorio proceso de desjerarquización, producto en parte de la propia necesidad de hacer crecer la cobertura educativa de manera imperiosa. A su vez la ansiedad de los dirigentes políticos y educativos por difundir sentimientos de nacionalidad de manera rápida y masiva, condujo a serios intentos de convertirlas en meras "especialistas en ritual". ${ }^{34}$

33 Sobre la evolución del aspecto académico de la docencia y la paradójica relación de los normalistas y otros docentes con respecto a la Escuela de Paraná y los estudios universitarios de pedagogía puede consultarse Carli: "Escenario educativo"

34 A esos claros intentos de diferenciación y subordinación no respondieron las maestras de manera pasiva. Muy por el contrario, emprendieron claras estrategias de revalorización de su actividad, que condujo a veces a conflictos con las autoridades educativas. La estricta regulación por parte del Consejo Nacional de Educación de las conferencias educativas debe ser entendida también como un intento de frenar los intentos de autonomía de las docentes. Este proceso se produjo bajo el telón de fondo de otros procesos también complejos; la creciente feminización de la profesión y la consolidación de unos peculiares vínculos históricos entre la familia popular y la escuela, que no serán abordados dentro del presente marco, pero que si es necesario tener presente.

Por otra parte debe señalarse también que ese "arrinconamiento" de las maestras en los escalones inferiores de la estructura docente implicaba al mismo tiempo una apertura a los sectores populares. Las facilidades que otorgaba el Estado para el acceso a la "carrera" docente significaban un importante aliciente económico y de ascenso social para muchas familias populares y un trabajo digno para muchas mujeres que veían en el una forma de liberación. Esta cuestión, sin duda contradictoria, producto de las ansias gubernamentales de crear un "ejército de maestras" iba a tener fundamentales consecuencias sociales y culturales en el siglo XX. 
A ese intento de diferenciación contribuyeron de una manera importante la ideología positivista, que tendía a ensalzar y primar a aquellos que se dedicaban a la ciencia, y la orientación efectiva que adquirió el sistema educativo, que pretendía no tanto "instruir" sino socializar de una manera general dentro de códigos nacionales que se consideraba en peligro de perderse..$^{35} \mathrm{La}$ "educación patriótica" implementada por unos gobiernos presurosos por obtener una homogeneidad mínima de la población en el menor tiempo posible necesitaba de un polo intelectual que fijara las grandes líneas y de otro compuesto por aquellas "especialistas en ritual".

Por otra parte, el carácter misional que se otorgó a la difusión de la educación laica, condujo a muchos a considerar que la mujer era el elemento ideal para llevarla a cabo. En tales argumentos subyacía fuertemente la idea de que la educación era en realidad una continuación de las tareas domésticas, lo que entraba en franca contradicción con la idea de lograr la profesionalización de todos los miembros del cuerpo docente. ${ }^{36}$ El ideal que en realidad se perseguía era el de una profesión escindida, con un sector claramente subordinado. El círculo de la diferenciación / jerarquización se cerró cuando el periodo de estudios necesario para obtener el título de maestro que en 1875 era de cinco años en 1875 se redujo primero a cuatro y después a tres años en 1887, fecha en que además se eliminaron los exámenes finales y cuando se suprimieron las becas para estudiantes hombres, con el argumento, refrendado por la realidad, de que una vez graduados optaban por ejercer otras actividades más prestigiosas y remuneradas. ${ }^{37}$ De manera curiosa y sin duda contradictoria se observa claramente como la promoción de la "educación patriótica" y del laicismo como "misión", y los intentos de consolidación de un sistema educativo homogéneo, se daban la mano con el afán diferenciador de la elite intelectual normalista.

35 Alliaud: Maestros; Bertoni: Patriotas, cosmopolitas.

36 Así en la Memoria de Educación del ministerio se observaba que las mujeres estaban mejor dotadas para inculcar la "educación patriótica" que se buscaba debido sobre todo a que "la mujer es siempre quien mejor guarda las tradiciones del pasado por que vive mas del sentimiento que de la especulación” Ministerio de Justicia; Culto e Instrucción Pública: Memoria correspondiente al ejercicio 1992, Buenos Aires 1893, págs. 527-528.

37 Ministerio de Justicia Culto e instrucción Pública: "Informe de la Escuela Normal de Santiago del Estero" en: Memoria correspondiente al ejercicio del año 1886, Buenos Aires 1887, pág. 102. Pocos años más tarde un comisionado del ministerio certificaba que "Los maestros normales en su gran mayoría aspiran a ser doctores y no cumplen con los compromisos contraídos con el gobierno" Comisionado Fitz Simon: "Informe especial", en Ministerio de Justicia Culto e Instrucción Pública: Memoria correspondiente al ejercicio del año 1892, Buenos Aires, 1893, pág. 341. 
Estos elementos fueron apuntalados por el esquema teórico normalista, basado en Pestalozzi, Spencer y más tarde en Herbart. Este derivó en una gran obsesión por el método y el control sistemático, tanto en la formación docente, como en el proceso educativo en general, lo que indujo históricamente a los normalistas a identificar en exceso pedagogía con didáctica. ${ }^{38}$ Por otra parte, el reduccionismo biologicista, otra de sus características más notorias, les permitía catalogar a la mayoría de los alumnos, en general hijos de inmigrantes, como pasivos. Ambas cuestiones, al limitar seriamente el espacio de lo espontáneo en el proceso de aprendizaje colocaban a la figura del maestro en el centro de la escena educativa. Con ello reforzaban los normalistas su propia posición institucional. Pero, al mismo tiempo, el pensamiento normalista proponía una férrea regulación de las actividades de los maestros, a los que, como ya he señalado consideraban en general indiferentes y poco entusiastas, debido sobre todo a su escasa formación. Afianzaban así, en cambio, su posición jerárquica.

Sin embargo, como grupo intelectual estos miembros de la cúpula docente jugaron un claro papel subordinado del que les resultó difícil salir a pesar de sus permanentes intentos. Curiosamente esa situación se vio reforzado por las propias estrategias de distinción que adoptaron con respecto al resto del cuerpo profesional al cual pertenecían. Al debilitar y desjerarquizar al conjunto disminuían el valor de sus apoyos naturales, que en otras circunstancias les hubieran permitido tener éxito en sus afanes. Para alcanzar la categoría de "doctores" no sólo era necesario distinguirse por su tarea intelectual al servicio de las altas esferas del estado, era también necesario, como los médicos y abogados, contar con un cuerpo sólido y prestigioso que los arroparan.

Puede decirse entonces que, a pesar de su papel de adalides en la lucha contra la ignorancia, en la formación de un tipo específico de ciudadano y en la promoción de la "educación patriótica", los normalistas encumbrados perdieron la batalla por el control de las abstracciones teóricas y por los espacios fundamentales de decisión de las políticas públicas en las áreas que aspiraban a controlar. Lo hicieron a mano de la que puede ser considerada la elite intelectual del momento, hombres de la máxima confianza de los respectivos gobiernos y pertenecientes en gran parte a grupos profesionales más homogéneos, sólidos y tradicionales: "los doctores", en general médicos y abogados, y pertenecientes en una medida importante a

38 Tedesco: Educación; Tedesco: "instancia educativa”; Solari, Manuel: Historia de la educación; Manganiello: Historia de la Educación. 
reconocidas familias de los sectores sociales más encumbrados. ${ }^{39}$ Sólo hay que repasar las listas de ministros y, sobre todo, de presidentes del Consejo Nacional de Educación y de miembros de comisiones específicas de importancia, como la de textos escolares, para observar la proporción decisiva de médicos y abogados, gran parte de ellos de la clase social más acomodada.

\section{Conclusión}

A modo de conclusión pueden señalarse algunas cuestiones de importancia. Los logros del sistema educativo que se consolidó en Argentina en la segunda mitad del siglo XIX fueron evidentes. Los más destacados fueron la significativa disminución del analfabetismo y el notorio incremento de la homogeneidad cultural de la población en el largo plazo. Sin embargo el sistema tuvo también rasgos típicos que presentaron una mayor ambivalencia y que tuvieron sin duda alguna serias consecuencias en el devenir social y cultural de la sociedad argentina del siglo XX.

El más significativo de estos rasgos fue la decisiva influencia que sobre la estructura profesional docente ejercieron en forma conjunta el fuerte centralismo y la prioridad que se dio a la difusión de sentimientos de nacionalidad. Esta influencia conjunta, fruto de tantos desfasajes y tensiones posteriores puede muy bien ejemplificarse por la propia historia de los docentes normalistas que se convirtieron en el alma del sistema pero no lograron situarse a su cabeza.

Ello fue así por varios motivos: Primero: Por que a medida que se acrecentaba para la elite la importancia de difundir sentimientos nacionales, más recurría a sus propios miembros para dirigir el proceso. Los más altos directivos, ministros y presidentes del Consejo pertenecieron en general a familias tradicionales y ninguno fue docente, como si en cambio la había sido Sarmiento. Segundo: Los docentes normalistas de alto rango perdieron la competencia que libraron con las elites de las profesiones tradicionales por el dominio de la abstracción teórica y el control académico de la cuestión educativa, elementos de gran importancia a la hora de legitimar de manera simbólica una actividad profesional. Tercero: Los norma-

39 Esto puede observarse de una manera clara revisando los nombramientos no sólo de ministros de educación sino fundamentalmente de presidentes del Consejo Nacional de Educación y de miembros de comisiones educativas específicas e importantes como, por ejemplo, la de textos escolares, o las propios Consejos Escolares de los distritos. 
listas, que por momentos se reconocían más como una elite estatal que profesional, se convirtieron en víctimas de sus propias estrategias de distinción dentro de la profesión docente. Sus críticas públicas, y a veces exacerbadas, acerca de la incapacidad de los maestros tendió a estratificar en exceso a la profesión y la debilitó en su competencia con otros sectores.

Esa falta de cohesión profesional que fue resuelta por los militares con la disciplina y por los médicos con el academicismo, no pudo ser solucionada por los docentes. Podríamos concluir diciendo que fue en buena medida el propio afán de los funcionarios normalistas de convertir al maestro en sujeto educativo controlado y de menor categoría, lo que les impidió convertirse en los líderes intelectuales que pretendían ser. 